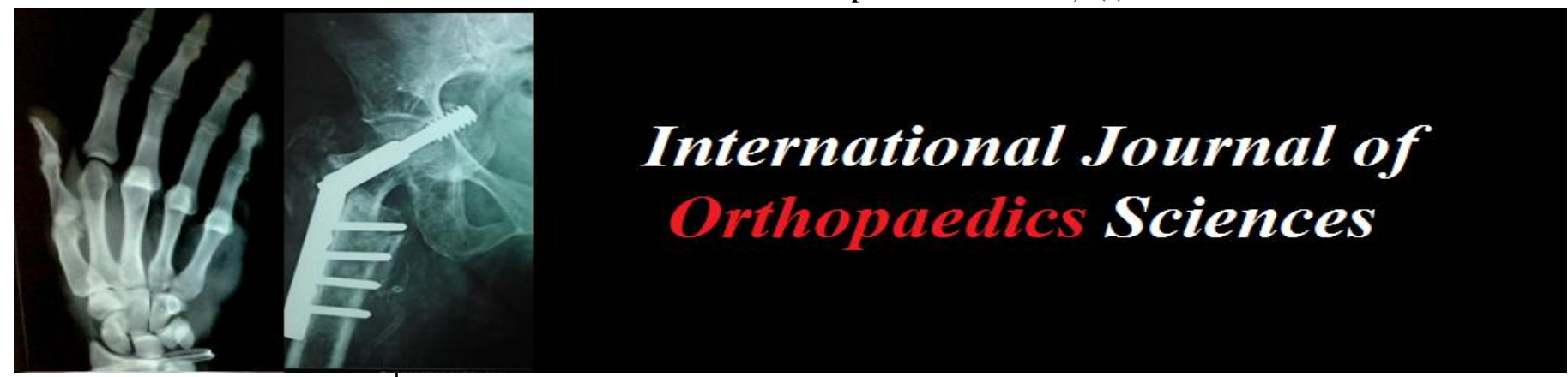

ISSN: $2395-1958$

IJOS 2017; 3(2): 32-37

(C) 2017 IJOS

www.orthopaper.com

Received: 09-02-2017

Accepted: 10-03-2017

Dr. Siddalingamurthy $\mathbf{G}$ M.B.B.S, M.S Orthopaedics, Professor, JSS Medical College and Hospitals, Mysuru, Karnataka, India

Dr. Ravi Kiran H G MBBS, MS Orthopaedics, Assistant Professor, JSS medical College and Hospitals, Mysuru,

Karnataka, India

Dr. Darshan C K

MBBS,

Jr. Resident Orthopaedics, JSS medical College and Hospitals, Mysuru, Karnataka, India

Dr. Abhilash Gowd B MBBS,

Jr. Resident in Orthopaedics, JSS medical College and Hospitals, Mysuru, Karnataka, India

Dr. Mruthyunjaya D.Ortho, M.S, DNB Orthopaedics, Professor, JSS Medical College and Hospitals, Mysuru, Karnataka, India
Correspondence

Dr. Darshan C K

MBBS,

Jr. Resident Orthopaedics, JSS medical College and Hospitals, Mysuru, Karnataka, India

\section{Functional outcome of proximal humeral interlocking system plating for displaced proximal humeral fractures in adults}

\author{
Dr. Siddalingamurthy G, Dr. Ravi Kiran H G, Dr. Abhilash Gowd B, \\ Dr. Darshan C K, and Dr. Mruthyunjaya
}

DOI: http://dx.doi.org/10.22271/ortho.2017.v3.i2a.09

\section{Abstract}

Objective: The objective of the study was to assess functional outcome of Proximal Humerus Inter Locking System (PHILOS) Plating in displaced proximal humeral fractures by Constant-Murley (Subjective and Objective) score.

Material and methods: The PHILOS plate was used for internal fixation of displaced proximal humeral fractures in 25 patients 11 females, 14 males; mean age 60.64 years range(28-90yrs). Fractures were caused by low-energy trauma fall from standing height in 16 patients, and by an road traffic accident in 9 patients. Involvement was on the right in 15 cases and on the left in 10 cases. Bone graft was used in 2 cases to prevent varus malalignment. All patients received a similar physical therapy program following internal fixation with the PHILOS plate. The patients were assessed clinically and radiographically at regular intervals of 6 weeks, 12 weeks and 6 months. Functional outcome was assessed using the Constant- Murley score. Complications during the follow-up period were recorded.

Results: 9 patients had Neer's four part fracture, 12 patients had 3 part fracture and 4 patients had 2 part fracture. After 6 months of follow up mean Constant and Murley score of 63.76 was achieved. Outcomes were excellent, good, moderate and poor in $2(8 \%), 3(12 \%), 14(56 \%), 6(24 \%)$ respectively. The most frequent complication seen was shoulder stiffness in 6 patients, malreduction in 4 and impingement in 4 patients.

Conclusion: Fixation of proximal humerus fractures with proximal humerus locking plates is associated with satisfactory functional outcomes in 2-part and 3-part and 4 part fracture. The incidence of complications is relatively high in 3 part and four part fractures. Advanced surgical skills and surgeon's experience are considered to be more critical for successful operative treatment.

Keywords: Proximal humerus fracture, fixation, Philos plate, Constant -Murley score, functional outcome

\section{Introduction}

Fractures occuring at or proximal to surgical neck of humerus are described as proximal humerus fractures. These fractures account for almost $7 \%$ of all fractures and make up $80 \%$ of all humerus fractures. In patients above the age of 65 years proximal humeral fractures are the second most frequent upper extremity fracture, and next to proximal femur and distal end radius fractures.

Various modalities of management for proximal humeral fractures which includes conservative and operative. Depending on displacement and angulation of fracture fragments management is planned. In this study Neer's proximal humerus fracture classification was followed.

Difficulties in surgery have been multifactorial, including osteoporotic bone, angular instability, implant impingement, bone loss, loss of reduction and backing out of screws. The indication for fixing such a fracture depends on the fracture pattern, quality of bone and the age and activity of the patient. The goal is to achieve near-anatomical reduction and stable fixation so as to achieve early mobilization.

They occur most commonly in the elderly. In younger patients, high-energy trauma is the cause and displacement is often more severe. PHILOS plate provides rigid fixation, more angular stability and early mobilisation. 
2. Aims and objectives: To study the functional outcome of PHILOS plating for displaced proximal humeral fractures by evaluating pain, activities of daily living, range of motion \& muscle power (Constant-Murley score).

\section{Material and methods}

3.1 Source of data

Patients coming to the casualty/ admitted under JSS hospital, Mysore under the Department of Orthopaedics.

\subsection{Type of study}

A prospective study

\subsubsection{Inclusion Criteria}

1. Patients age more than 18 years.

2. Failure of conservative management.

\subsubsection{Exclusion Criteria:}

1. Pathologic fractures from primary or metastatic tumours.

2. Patients age less than 18 years.

3. Open fractures.

4. Methods of collection of data:

- Duration of study: September 2014 to May 2016

- Sample size: 25

- Area of study: Department of Orthopedics, JSS hospital, Mysore

Patients who came to the casualty/emergency services or patients admitted in the ward who meet the inclusion criteria were included in the study. A detailed history focusing on the mode of injury was taken followed by a detailed general and local examination.

After seeking permission, proformas either in English or the local language were filled. Following consent and surgery, patients were followed up at regular intervals. Details were noted in a pre formatted proforma and the data analysed.

\subsection{Methodology}

\subsubsection{Preoperative:}

Patients admitted with displaced proximal humeral fractures were examined and x-rays of the shoulder in AP and axial views were obtained. Vascular and nerve injuries were ruled out. U slab was applied to immobilize the fracture in all cases. Fractures were classified according to Neer's classification. Patient was advised to perform both forearm supination, pronation movements and wrist and finger movements. All patients were operated within 1 week from the time of injury depending on anesthetic fitness, Operation theater and implant availability.

\subsubsection{Type of anesthesia - general anesthesia was used.}

\subsection{Operative procedure}

\subsubsection{Patient positioning}

Beach chair position was used in all cases once the general anesthesia was administered.

\subsubsection{Approach- Deltopectoral Approach}

All cases in our study had undergone surgery through the deltopectoral approach which is considered the workhorse for reconstructive shoulder surgery. An incision starting over the coracoid process and advanced along the deltopectoral groove with subsequent identification and lateral reflection of the cephalic vein. A full-thickness skin flap is developed medially at the proximal extent of the incision to about 1 to $2 \mathrm{~cm}$ medial to the coracoid process. The cephalic vein was retracted laterally. The subdeltoid space is identified and fracture hematoma was cleared. After the identification of the long head of the biceps on the anterior aspect of the proximal shaft which will facilitate fracture identification and reduction and plate placement.

\subsubsection{Philos plate and screw fixation}

After exposing proximal humerus, tuberosities and humeral head were reduced along with rotator cuff tendons tagged with ethibond sutures to tie to final construct. Humeral shaft, tuberosities and humeral head were temporarily fixed with $\mathrm{k}$ wires. If dislocation was there it was reduced. Philos plate was put lateral to bicipital groove and fixed with locking and cancellous screws. Bone graft from iliac crest was put for two of the cases where there was bone loss leading the fracture to reduce in varus mal alignment.

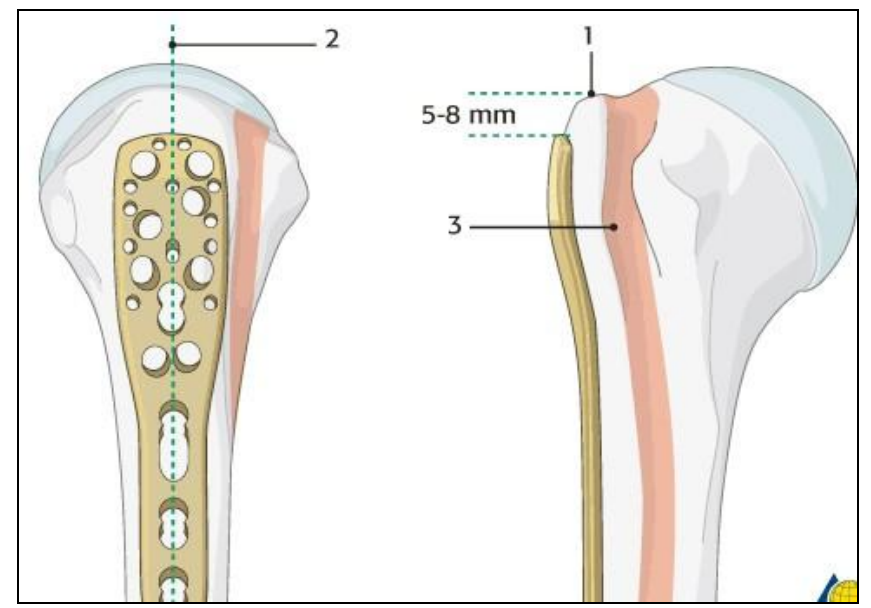

Fig 1: correct positioning of (philos) plate

The correct plate position is

1. About 5-8 $\mathrm{mm}$ distal to the top of the greater tuberosity.

2. Aligned properly along the axis of the humeral shaft.

3. slightly posterior to the bicipital grove $(2-4 \mathrm{~mm})$
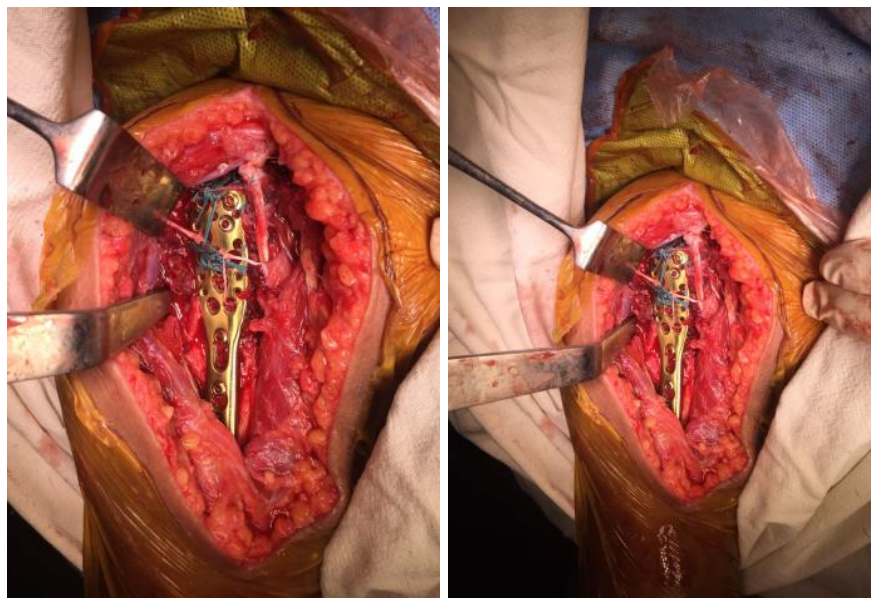

Fig 2: Intra operative fixation of proximal humerus fracture with philos plate and rotator cuff anchored to plate with ethibond sutures.

\subsubsection{Postoperative protocol}

Patients were initially observed in recovery room then shifted to ward. Intravenous second generation cephalosporins continued till 2 days post operatively. Shoulder immobilizer was used after surgery till 4 weeks. Sutures were removed at $10^{\text {th }}$ day post operatively. Active range of movements of 
elbow and wrist were advised immediate post operatively. Patients were discharged after 10 days were advised to follow up after 6 weeks. Passive and assisted passive range of movements were advised at $4^{\text {th }}$ week and active range of movements were encouraged at 6 weeks and should be able to achieve 90 degrees of forward elevation and rotation from the hand placed on the chest to neutral with the hand pointing straight forward. As the patient adapts to these exercises, they can be continued in the sitting or standing position. In addition, Codman pendulum exercises can be performed for passive range-of-motion exercises of the shoulder. Cuff strengthening exercises started 3 months after the follow up according to radiographic and clinical healing.

\subsection{Follow up}

Patients had been followed up at 6 weeks, 12 weeks and at 6months for functional assessment with each follow up clinical and radiological evaluation has been done.

Functional outcomes for pain, range of motion and muscle power, and function are assessed using the Constant and a Murley scoring system.
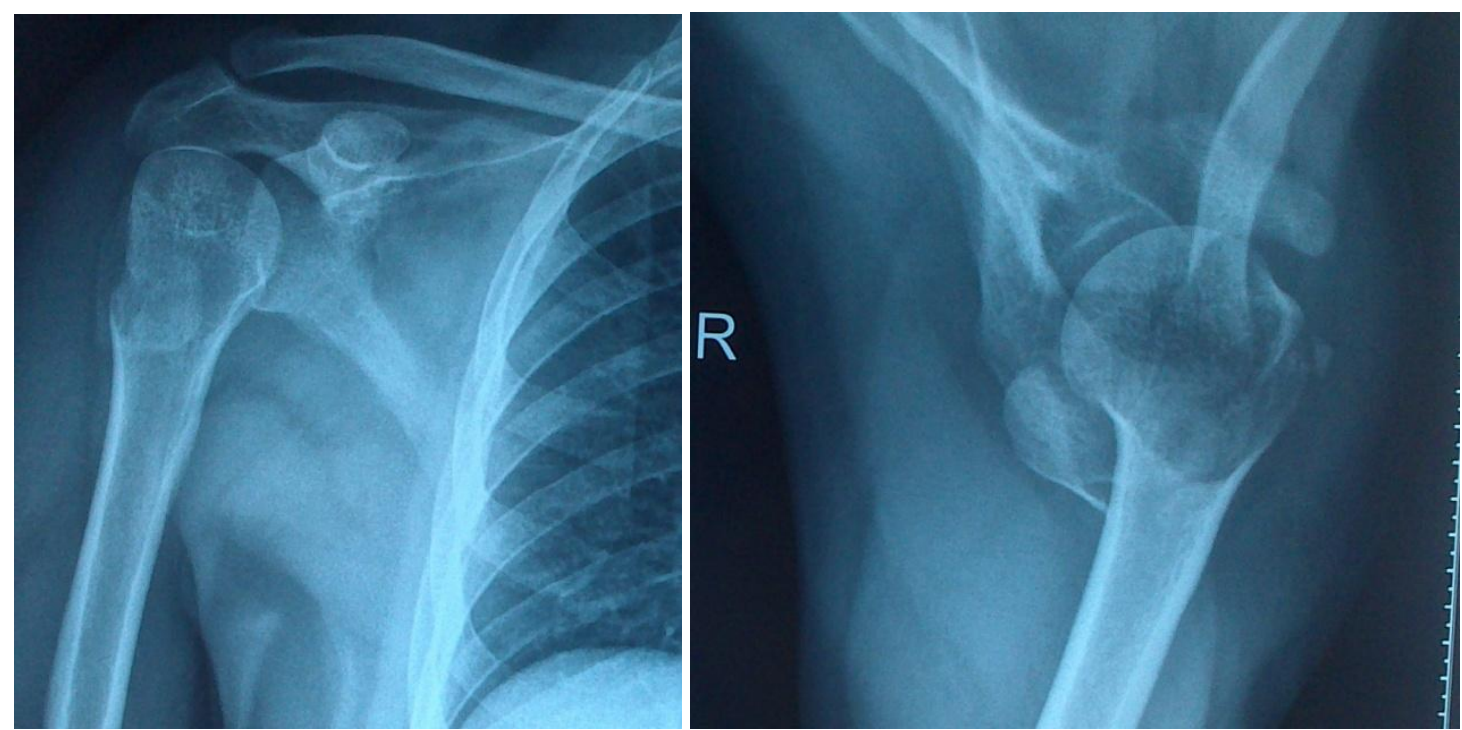

\section{Post op radiograph}

\subsubsection{Functional grading used in the evaluation 4.3.1.1 Constant and murley scoring system}

The European Society for Shoulder and Elbow Surgery adopted the scoring system of C Constant and A Murley. This scoring system consists of four variables that are used to assess the function of the shoulder. The right and left shoulders are assessed separately. The subjective variables are pain and ADL (sleep, work, recreation / sport) which give a total of 35 points. The objective variables are range of motion and strength which give a total of 65 points. Altogether there are a total of 100 points

\subsubsection{Interpreting constant and murley scoring system}

Excellent: Score between 86 and 100

Good: Score between 71 and 85

Moderate: Score between 56 and 70

Poor: Score less than 55

A male patient after $h / o$ of rta came with pain in right shoulder and diagnosed as neer's two part fracture.

Pre op radiograph

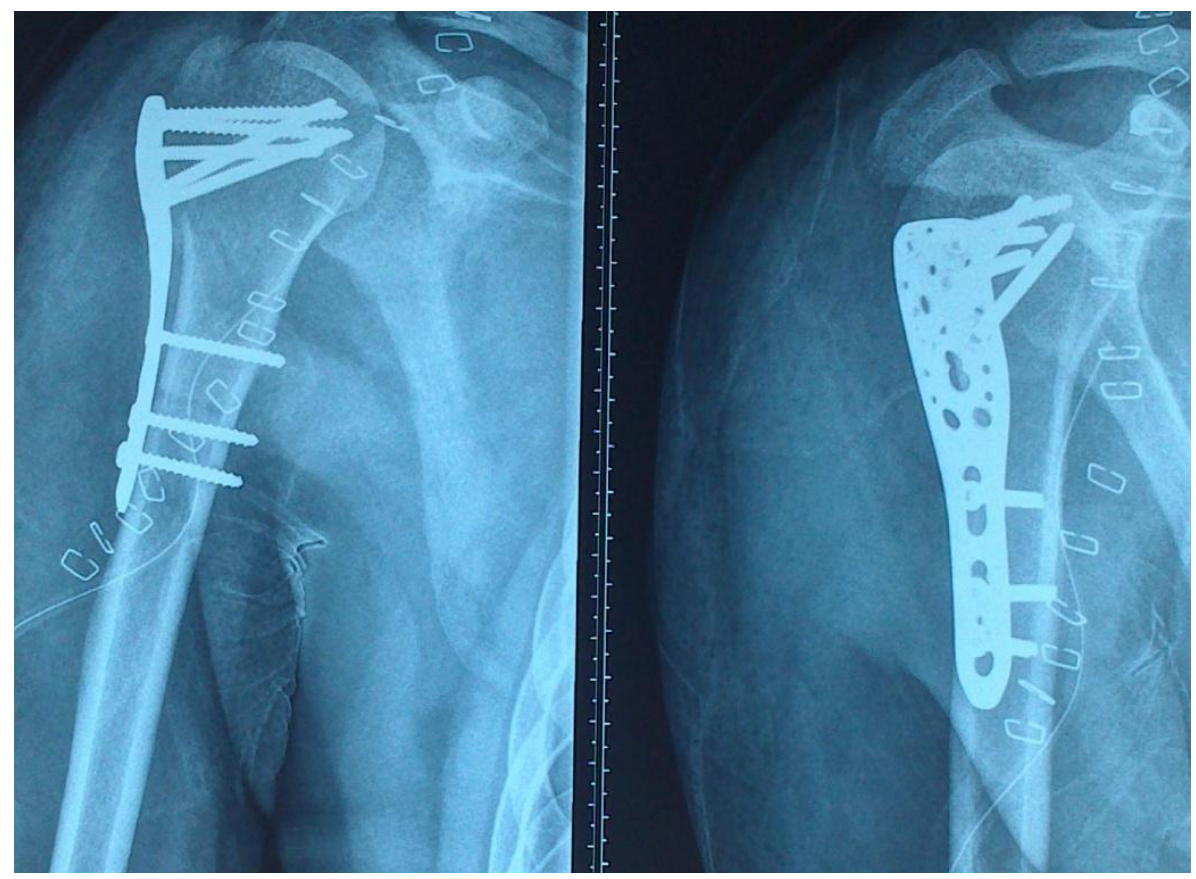




\section{Clinical photograph at 4 months}
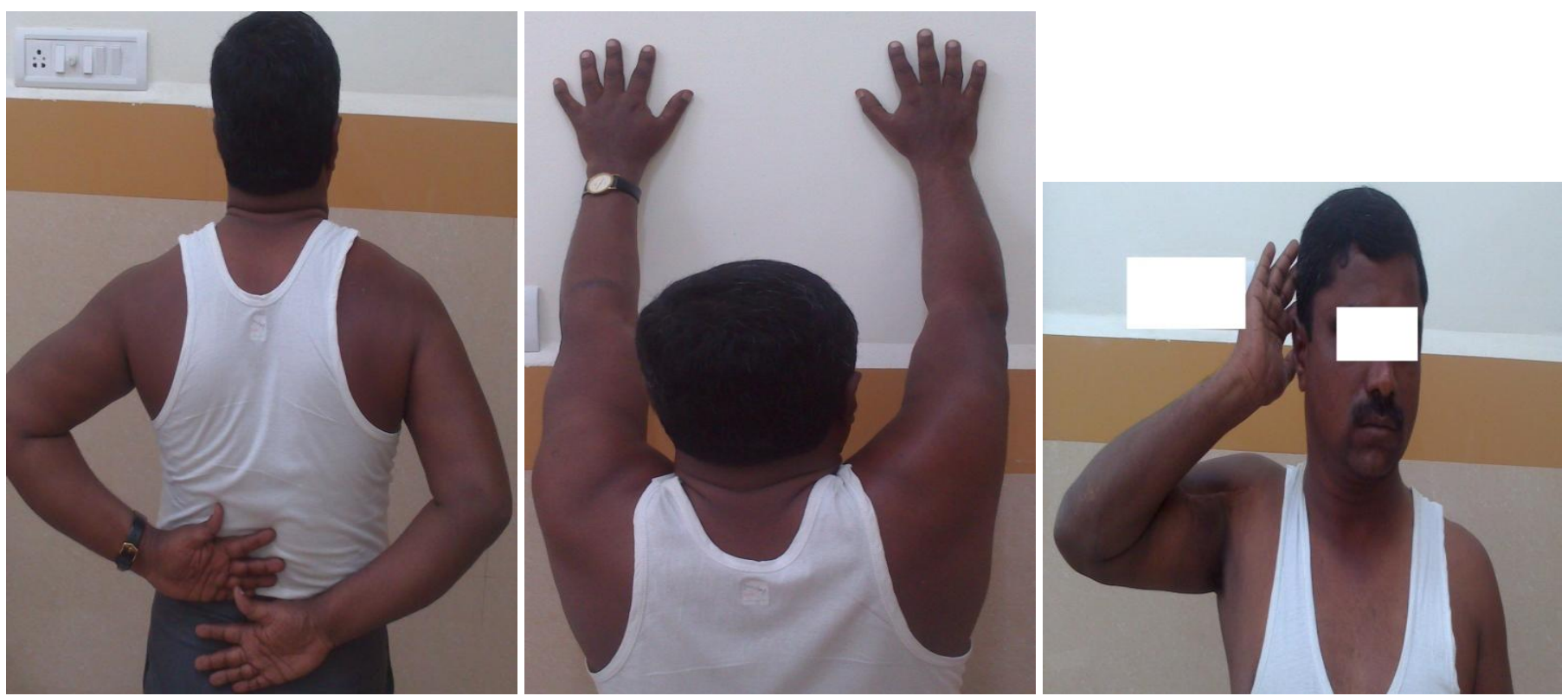

\section{Results}

The following observations were made from the data collected during the study.

Table 1: Type of fracture

\begin{tabular}{|c|c|c|}
\hline Neer's classification & Count & Column N \% \\
\hline Two Part & 4 & $16.0 \%$ \\
\hline Three Part & 12 & $48.0 \%$ \\
\hline Four Part & 9 & $36.0 \%$ \\
\hline
\end{tabular}

In our study Two Part fractures of 4 (16\%)

Three part fractures of $12(48 \%)$

Four part fractures of $9(36 \%)$

Table 2: Complications

\begin{tabular}{|c|c|c|}
\hline Complications & Count & Column N \% \\
\hline Impingement & 3 & $11.5 \%$ \\
\hline Impingement, malreduction & 1 & $3.8 \%$ \\
\hline Malreduction & 1 & $3.8 \%$ \\
\hline Nill & 15 & $57.7 \%$ \\
\hline Stiffness & 4 & $15.4 \%$ \\
\hline Stiffness, malreduction & 2 & $7.7 \%$ \\
\hline
\end{tabular}

In our study Complications were noted in 10 patients of which most common complication noted was stiffness of about 4 (15.4\%) patients.

Impingement was noted in $3(11.5 \%)$ patients

Varus malreduction was seen in $1(3.8 \%)$ patients

Combination of malreduction with stiffness was seen in $2(7.7 \%)$ patients.

Combination of impingement and malreduction was seen in $1(3.8 \%)$ patients

Table 3: Mean Constant and Murley score

\begin{tabular}{|c|c|c|c|c|c|}
\hline C and M score & Mean & Standard Deviation & Median & Percentile 25 & Percentile 75 \\
\hline 6_wks & 28.12 & 6.15 & 30.00 & 28.00 & 30.00 \\
\hline 12_wks & 50.15 & 7.25 & 48.50 & 46.00 & 55.00 \\
\hline 6months & 63.76 & 10.35 & 62.50 & 57.00 & 68.00 \\
\hline
\end{tabular}

In our study Mean Constant and Murley score at the end of 6 weeks was 28.12 \pm 6.15 SD

Mean Constant and Murley score at the end of 12 weeks was 50.15 \pm 7.25 SD

Mean Constant and Murley score at the end of 6 months was $63.76 \pm 10.35$ SD 


\section{Discussion}

Operative treatment of comminuted and displaced proximal humeral fractures, especially in osteoporotic bone, has been a complex and challenging problem. Different techniques have been described for fixation of comminuted and displaced proximal humeral fractures ${ }^{[30-33]}$. All these techniques have been associated with a varying rate of complications such as cut-out or back-out of the screws and plates, nonunion, avascular necrosis, and fractures distal to the plate ${ }^{[34,35,36]}$. Functional outcome not only depends on the quality of bone stock, but also on the stability provided by the implant. In an internal locking system like the PHILOS plate, all forces are transmitted from the bone via the locking head screws to the blade, and vice versa. Hence, the principle of fixed angle plates enables a gain in torsional stiffness and stability, and may therefore promote a superior outcome ${ }^{[37]}$. The present study was conducted to evaluate clinical outcome following PHILOS plate fixation and to assess potential complications during the follow-up. To date, early results of locking plate fixation of proximal humeral fractures have been reported ${ }^{[38,}$ $41,42]$.

We could achieve a mean Constant Murley score of 63.76 due to various complications encountered with plates. Various studies had reported varying results. Thyagarajan et al in their study on 30 patients showed an overall average Constant score of 57.5. The mean age in their series was 58 years (range 19-92 years) and fractures were Neer's 2-part, 3-part, and 4-part fractures. Rizwan Shahid et al in their study reported that the results of PHILOS plating were equally good in all patients but functional outcome was better in younger age group. They reported that with associated dislocation the results were deteriorated. These results were comparable to our study. In one prospective study, mean constant score was 68.31 in 19 patients ${ }^{[13]}$. Kettler et al reported a ConstantMurley score between 52 to 72 points after ORIF with the PHILOS plate ${ }^{[42]}$. Hente et al reached a mean ConstantMurley score of 55 points in these specific fracture types, which was lower than for fractures without dislocation ${ }^{[36]}$. However, the systematic review by Thanasis et al reported an overall Constant score of 74.3 and most of other studies have reported good functional outcomes and recommended the use of locking plates for proximal humerus fractures especially in elderly patients with poor bone quality. This leads us to believe that application of locking plate technology for proximal humerus fractures has a steep learning curve and appropriate surgical technique is very important for achieving good functional outcome.

In our study also the mean Constant score for 4-part fractures was 60.30 which were inferior as compared to 2-part and 3part fractures (68 and 64.50 respectively). The results of two studies indicated an advantage in functional outcomes favouring shoulder hemiarthroplasty compared with ORIF with a locking plate in 4-part fracture ${ }^{[39,40]}$. Post operatively, various complications were observed. Stiffness of shoulder was observed in 6 patients $(24 \%)$ and was found to be the commonest complication in our study. None of our patients had screw perforation leading to implant loosening. We thus found that a varus malalignment was causing loss of fixation with poor outcome in four patients in similar to one prospective study ${ }^{[13]}$ and must be avoided intra-operatively at any cost. We in our patients attempted to achieve correct anatomic reduction of the fragments but still had a high percentage of patients with this complication.

Based on our observations, inadequate positioning of the implant and severe comminution of fracture fragments resulted in reduced functional outcome. Hence, to improve functional results, we consider plate positioning and anatomical reduction of fracture were to be of utmost importance when using PHILOS plate fixation.

The limitation of this study is lack of a control group and less follow up period.

\section{Conclusion}

Fixation of proximal humerus fractures with proximal humerus locking plates is associated with satisfactory (moderate) functional outcomes. Based on our observations, inadequate positioning of the implant resulted in reduced functional outcome. Hence, to improve functional results, we consider plate positioning to be of utmost importance when using PHILOS plate fixation. As the complex four part fracture dislocations are difficult to achieve anatomical reduction thorough knowledge of surgical anatomy of proximal humerus is required and might require CT scan shoulder for better visualization of fracture displacement preoperatively. Post operative rehabilitation and encouragement for physical therapy also plays role in better functional outcomes.

\section{References}

1. David S. Thyagarajan, Samarth J. Haridas, Denise Jones, Colin Dent, Richard Evans, Rhys Williams.Functional outcome following proximal humeral interlocking system plating for displaced proximal humeral fractures.Int $\mathbf{J}$ Shoulder Surg. 2009; 3(3):57-62.

2. Rizwan HAHID S, Abid USHTAQ M, Julian ORTHOVER N, Mohammad AQSOOD M. Outcome of proximal humerus fractures treated by PHILOS plate internal fixation Experience of a District General Hospital. ActaOrthop. Belg. 2008; 74:602-608

3. Jan-Magnus Björkenheim, Jarkko Pajarinen, Vesa Savolainen. Internal fixation of proximal humeral fractures with a locking compression plate. Acta Orthop Scand. 2004; 75(6):741-745

4. Moonot P, Ashwood N, Hamlet M. Early results for treatment of three- and four- part fractures of the proximal humerus using the PHILOS plate system.J Bone Joint Surg [Br]. 2007; 89-B:1206-9.

5. Geiger EV, Maier M, Kelm A, Wutzler S, Seebach C, Marzi I. Functional outcome and complications following PHILOS plate fixation in proximal humeral fractures. Acta Orthop Traumatol Turc. 2010; 44(1):1-6. doi: 10.3944/AOTT.2010.2270.

6. Fazal MA, Haddad FS. Philos plate fixation for displaced proximal humeral fractures. J Orthop Surg (Hong Kong). 2009; 17(1):15-8.

7. Iacobellis C, Fountzoulas K, Aldegheri R. Plating of proximal fracture of the humerus. Musculoskelet Surg. 2011; 95(1):S43-8. doi: 10.1007/s12306-011-0103-1. Epub 2011 Mar 4

8. Strohm PC, Helwig P, Konrad G, Südkamp NP. Locking Plates in Proximal Humerus Fractures. 410/ acta chirurgiae orthopaedicae/et traumatologiae čechosl. 2007; 74:410-415.

9. Andrew Crenshaw jr H. and Edward A. Prez Proximal humerus fractures from Campbell $\mathrm{s}$ operative orthopaedics 11th edition, 3:3377-3384.

10. Rizwan SHAHID, Abid MUSHTAQ, Julian NORTHOVER, Mohammad MAQSOOD. Outcome of proximal humerus fractures treated by PHILOS plate internal fixation Experience of a District General 
Hospital. Acta Orthop. Belg. 2008; 74:602-608

11. Brunner Felix MD, Sommer Christoph MD, Bahrs Christian MD, Heuwinkel Rainer Hafner MD, Christian MD et al. Open Reduction and Internal Fixation of Proximal Humerus Fractures Using a Proximal Humeral Locked Plate: A Prospective Multicenter Analysis.journal of orthopaedic trauma March. 2009; 23(3):163-167.

12. Kettler et al. Treatment of proximal humeral fractures with the PHILOS angular stable plate. Presentation of 225 cases of dislocated fractures.

13. Owsley KC et al. University of Rochester Medical Center, 601 Elmwood Avenue, Box 665, Rochester, NY 14642, USA. Fracture displacement and screw cutout after open reduction and locked plate fixation of proximal humeral fractures. J Bone Joint Surg Am. 2008; 90(4):862.

14. Pearl ML, Volk AG. Coronal plane geometry of the proximal humerus relevant to prosthetic arthroplasty. J Shoulder Elbow Surg. 1996; 5(4):320-326.

15. Mochizuki T, Sugaya H, Uomizu M et al. Humeral insertion of the supraspinatus and infraspinatus. New anatomical findings regarding the footprint of the rotator cuff. J Bone Joint Surg Am. 2008; 90(5):962-969.

16. Iannotti JP, Gabriel JP, Schneck SL et al. The normal glenohumeral relationships. An anatomical study of one hundred and forty shoulders. J Bone Joint Surg Am. 1992; 74(4):491-500.

17. Brooks CH, Revell WJ, Heatley FW. Vascularity of the humeral head after proximal humeral fractures. An anatomical cadaver study. J Bone Joint Surg Br. 1993; 75(1):132-136.

18. Keser S, Bölu"kbasi S, Bayar A et al. Proximal humeral fractures with minimal displacement treated conservatively. Int Orthop. 2004; 28(4):231-234.

19. Rommens PM, Heyvaert G. Conservative treatment of subcapital humerus fractures. A comparative study of the classical Desault bandage and the new Gilchrist bandage. Unfallchirurgie. 1993; 19(2):114-118.

20. Hertel R, Hempfing A, Steihler M et al. Predictors of humeral head ischemia after intracapsular fracture of the proximal humerus. J Shoulder Elbow Surg. 2004; 13(4):427-433.

21. Bastian JD, Hertel R. Initial post-fracture humeral head ischemia does not predict development of necrosis. J Shoulder Elbow Surg. 2008; 17(1):2-8.

22. Mont MA, Maar DC, Urquhart MW et al. Avascular necrosis of the humeral head treated by core decompression. A retrospective review. J Bone Joint Surg Br. 1993; 75(5):785-788.

23. Dines DM, Warren RF, Altchek DW et al. Posttraumatic changes of the proximal humerus: Malunion, nonunion, and osteonecrosis. Treatment with modular hemiarthroplasty or total shoulder arthroplasty. J Shoulder Elbow Surg. 1993; 2(1):11-21.

24. Boileau P, Trojani C, Walch G et al. Shoulder arthroplasty for the treatment of the sequelae of fractures of the proximal humerus. J Shoulder Elbow Surg. 2001; 10(4):299-308.

25. Court-Brown CM, McQueen MM. Nonunions of the proximal humerus: their prevalence and functional outcome. J Trauma. 2008; 64(6):1517-1521.

26. Healy WL, Jupiter JB, Kristiansen TK et al. Nonunion of the proximal humerus. A review of 25 cases. J Orthop Trauma. 1990; 4(4):424-431.
27. Scheck M. Surgical treatment of nonunions of the surgical neck of the humerus. Clin Orthop Relat Res. 1982; (167):255-259.

28. Galatz LM, Iannotti JP. Management of surgical neck nonunions. Orthop Clin North Am. 2000; 31(1):51-61.

29. Connor PM, Flatow EL. Complications of internal fixation of proximal humeral fractures. Instr Course Lect. 1997; 46:25-37.

30. Court-Brown CM, Garg A, McQueen MM. The epidemiology of proximal humeral fractures. Acta Orthop Scand. 2001; 72:365-71.

31. Robinson CM, Page RS. Severely impacted valgus proximal humeral fractures: Results of operative treatment. J Bone Joint Surg Am. 2003; 85:1647-55.

32. Wanner GA, Wanner-Schmid E, Romero J, Hersche O, von Smekal A, Trentz $\mathrm{O}$ et al. Internal fixation of displaced proximal humeral fractures with two one-third tubular plates. J Trauma. 2003; 54:536-44.

33. Park MC, Murthi AM, Roth NS, Blaine TA, Levine WN, Bigliani LU. Two-part and three-part fractures of the proximal humerus treated with suture fixation. J Orthop Trauma. 2003; 17:319-25.

34. Schmal H, Klemt C, Sudkamp NP. [Evaluation of shoulder arthroplasty in treatment of four-fragment fractures of the proximal humerus]. Unfallchirurg German. 2004; 107:575-82.

35. Fankhauser F, Boldin C, Schippinger G, Haunschmid C, Syzszkowitz R. A new locking plate for unstable fractures of the proximal humerus. Clin Orthop Relat Res. 2005; 430:176-81.

36. Hente R, Kampshoff J, Kinner B, Fuchtmeier B, Nerlich M. [Treatment of dislocated 3- and 4-part fractures of the proximal humerus with an angle-stabilizing fixation plate][in German]. Unfallchirurg. 2004; 107:769-82.

37. Thanasas C, Kontakis G, Angoules A, Limb D, Giannoudis P. Treatment of proximal humerus fractures with locking plates: a systematic review. J Shoulder Elbow Surg. 2009; 18(6):837-44.

38. Cai M, Tao K, Yang C, Li S. Internal fixation versus shoulder hemiarthroplasty for displaced 4-part proximal humeral fractures in elderly patients. Orthopedics. 2012; 35(9):e1340-6.

39. Spross C, Platz A, Erschbamer M, Lattmann T, Dietrich M. Surgical treatment of Neer Group VI proximal humeral fractures: retrospective comparison of PHILOS $®$ and hemiarthroplasty. Clin Orthop Relat Res. 2012; 470(7):2035-42.

40. Sproul RC, Iyengar JJ, Devcic Z, Feeley BT. A systematic review of locking plate fixation of proximal humerus fractures. Injury. 2011; 42(4):408-13.

41. Spross C, Platz A, Rufibach K, Lattmann T, Forberger J, Dietrich M. The PHILOS plate for proximal humeral fractures--risk factors for complications at one year. J Trauma Acute Care Surg. 2012; 72(3):783-92.

42. Kettler M, Biberthaler P, Braunstein V, Zeiler C, Kroetz M, Mutschler W. [Treatment of proximal humeral fractures with the PHILOS angular stable plate. Presentation of 225 cases of dislocated fractures]. Unfallchirurg German, 2006; 109:1032-40.

43. Aggarwal S, Bali K, Dhillon MS, Kumar V, Mootha AK. Displaced proximal humeral fractures: an Indian experience with locking plates. J Orthop Surg Res. 2010; 5:60. 